\title{
Comparing the Efficiency of Special Teaching Methods by Means of Standardized Tests
}

\section{Samuel S. Brooks}

To cite this article: Samuel S. Brooks (1921) Comparing the Efficiency of Special Teaching Methods by Means of Standardized Tests, The Journal of Educational Research, 4:5, 337-346, DOI: 10.1080/00220671.1921.10879214

To link to this article: http://dx.doi.org/10.1080/00220671.1921.10879214

曲 Published online: 15 Dec 2014.

Submit your article to this journal \lceil

Џll Article views: 1 


\title{
JOURNAL of EDUCATIONAL RESEARCH
}

VOLUME IV

DECEMBER, 1921

NUMBER 5

COMPARING THE EFFICIENCY OF SPECIAL TEACHING METHODS BY MEANS OF STANDARDIZED TESTS ${ }^{1}$

\author{
Samuel S. Brooks \\ District Superintendent, Winchester, New Hampshire
}

In the last article five principal factors in a teacher's efficiency were distinguished-namely, (1) managing ability, (2) natural aptitude, (3) method of teaching, (4) interest and industry, and (5) personality. The position was taken that no one of these five factors can be accurately and objectively measured independently of any or all of the other factors.

Although method was one of the factors mentioned we nevertheless now propose to measure the efficiency of methods. Note, however, that we do not propose to do so independently of the other factors.

In general the efficiency of a teacher and the efficiency of her methods are pretty much inseparable. It is a mooted question whether or not there can be a good teacher without good teaching methods. We hear it argued, for example, that a good teacher with a poor method will accomplish more than a poor teacher with a good method. This argument implies that good teachers using poor methods may secure better results than poor teachers using good methods, in the same way that a good carpenter with few and poor tools can do a better job than can the novice with the best and most complete set of tools obtainable. We must admit that there is much truth in the argument. Sometimes we find that a teacher who is ignorant of approved methods but who has great natural ability is obtaining better results than another teacher who is without natural aptitude but who, perhaps with all the advantages of normal training, is using or rather misusing,

1 This is the seventh article by Superintendent Brooks on the general topic, "Putting Standardized Tests to Practical Use in Rural Schools." 
the most approved modern methods. One has the true teaching instinct and ability to apply general principles and the other lacks these advantages.

Whatever may be the actual relations between good and poor teachers and good and poor methods, we can all agree, I think, that the best teachers are those who combine natural aptitude with thorough knowledge of up-to-date methods together with skill in applying them so as to realize their possibilities. And although we cannot measure the efficiency of a teacher's methods entirely apart from consideration of her general ability, there is a way, nevertheless, by which we can with the help of standardized tests obtain fairly accurate comparisons of the efficiency of various special methods, taking at the same time full cognizance of the teacher's general ability.

This can be done somewhat as we solve simultaneous equations in algebra - that is, by manipulating the various quantities so as to eliminate all but one of the unknowns. The value of the remaining unknown is readily found after the others are equalized so as to cancel each other. Yet it cannot be said that the eliminated quantities are ignored. The manipulations required to bring about the conditions suitable for their elimination give them their full force in evaluating the result.

And so, if we are to find the relative values of two or more special teaching methods, we must equalize as far as possible the conditions under which those methods are tried out, thus eliminating all the unknown quantities but one. The chief of these external conditions that would affect the accuracy of our results are the general ability of the teachers, the average mental abilities of the several groups of pupils, and the time devoted to class work with the method.

Now, there are two ways in which we may want to compare methods. We may want to discover which of two or more special methods of teaching a subject will give the best results when used by teachers of equal general ability or we may want to learn which of two or more special methods can be used to best advantage by a certain teacher.

To illustrate the first case, suppose we wanted to compare the results of drill in the fundamental operations of arithmetic as conducted in the usual more or less unorganized manner and without much regard for the special difficulties involved in definite types of 
examples, with results of drill in the same operations by means of the Courtis Standard Practice Tests. To do this we should first choose our teachers for the trial. Their general ability should be as nearly equal as possible in order to eliminate so far as may be any inaccuracy in our conclusions due to differences in ability. Two teachers with approximately equal ratings by the method described in my last article would serve admirably. One should have had no experience with, and if possible no knowledge of, the Courtis Standard Practice Tests or of similar practice material, while the other should have had experience in their use and knowledge of their basic principles. It would not do to have the same teacher try to handle both methods because, on the one hand, if she had had experience with the practice tests, the defects of the haphazard procedure would be largely nullified by her knowledge of the principles underlying them; while, on the other hand, if she did not have such knowledge and experience, the advantages of the Courtis method would in some measure be lost.

The next step is to choose two groups of pupils. These groups should be neither too large nor too small; neither large enough to be cumbersome to handle as a class nor small enough to make average scores meaningless. From ten or twelve to twenty in a group is probably about right. The pupils in both groups should be in the same grade, and the average mental ages and average intelligence quotients of the two groups should be as nearly equal as possible. The pupils' mental ages and intelligence quotients are obtained of course by means of intelligence tests, some uses of which will be discussed in a later article.

As soon as the pupils have been selected, they should be carefully tested by means of standardized tests in the fundamentals, and their scores should be recorded. The testing of both groups and the scoring of the papers should be done by the same person, preferably a person experienced in such work. The period of drill should begin as soon as the tests have been given. Care should be taken to see that, in each group, exactly the same amount of time is devoted to drill in the fundamental operations each day. At the end of eight or ten weeks the tests should be given again, the scores recorded, and the progress of the two groups compared. The difference in progress of the two groups will approximate the difference in efficiency of the two methods. 
The degree of accuracy of the results will depend upon the care with which the tests are given and the degree to which the conditions of the drill work are equalized. It is an open question whether or not the teachers themselves should be informed of the main purpose in view-that is, the purpose of comparing the efficiency of the two methods. If we could be perfectly sure that both teachers would be thoroughly interested and honest about the experiment it would undoubtedly be wise to seek their intelligent cooperation, since by so doing we should be more likely to get the best possible results from both methods. But if, thinking that their reputations are at stake, one or both are likely to be tempted to stretch the time limit for daily drill or to persuade the pupils to drill themselves for speed and accuracy outside of class, then it will probably be better to leave them in blissful ignorance of the main plot, merely seeing to it that each teacher devotes the same amount of time to class drill in the fundamentals each day. In this way one can infer what each of the methods would accomplish under everyday working conditions in the hands of equally competent teachers. If one is particularly desirous of getting the best results of which either method is capable, this purpose may perhaps be accomplished by asking each teacher separately to do her very best.

This particular problem was worked out in my district last year with rather interesting and fairly conclusive results. The Courtis Standard Practice Tests were not in use in the district but, wishing to introduce them the following September, I planned ahead to have the stage set for their appearance. That is, before the practice tests were introduced generally, I wanted if possible to prove definitely that better results could be accomplished by their use with less drudgery for both teachers and pupils.

This was before the teachers' ratings had been computed so I did not have their ratings for guides in selecting the teachers to carry out the experiment. But I did have the records of progress for each school as shown by the September and February tests. Wishing to secure as accurate results as possible under the circumstances, I tried the experiment in each of three different towns. To handle the work with the practice tests three teachers were selected (one in each town) who had shown interest and capability in adapting new ideas to classroom use and whose schools had made normal progress during the first half of the year. Five 
weeks before the end of the winter term these three teachers were furnished with the Courtis Standard Practice Tests, Teacher's Manuals, and Students' Practice Pads. I showed them how to use the tests, pointed out their advantages, and explained the principles underlying them. Then I told them that for special reasons of which they would be informed in due time, I was anxious to have them become as expert as possible in using the tests by the end of that term. They assured me that they would do their best and I believe they did. At any rate, they did exceedingly well.

The other three teachers, one in each town, were chosen because their schools had also shown about normal progress for the first half of the year, and because of the further fact that they were all teachers of many years' experience, somewhat set in their ways and not taking kindly to new ideas, but withal hardworking, trustworthy, and capable of doing very good work in their own ways. In other words, they were good old-fashioned teachers.

The intelligence tests had been given by this time throughout the district and I hastened to get the mental ages and intelligence quotients of all the pupils for use in selecting the several groups. They were finally selected according to the plan outlined above except that the grades in any one school were too small to allow of groups of ten pupils being selected from the same grade in such a way that the six groups would all average the same in both mental ages and I. Q.'s. However, the conditions regarding M. A.'s and I. Q.'s were strictly observed and allowed for. The lowest mental age in any group was 10 years, 9 months and the highest was 11 years, 5 months. The I.Q.'s ranged from 97 to 105 .

Using the Woody scales for measuring the ability of pupils in the fundamental operations, I gave the first tests to the six picked groups during the first week of the spring term, and corrected and scored them myself, tabulating the average scores for each group in each subject as shown in Table $\mathrm{I}$, in the columns marked "A." At the time I gave the tests to each group of pupils, I had a talk with their teacher, telling her that for very important reasons I wanted her to see how much improvement she could bring about in that particular group during the ensuing twelve weeks by drilling the pupils together just fifteen minutes each day for speed and accuracy in the fundamental operations of arithmetic. The 
TABLE I. AVERAGE SCORES IN THE WOODY SCALES

(a) Groups not Using Practice Tests

\begin{tabular}{|c|c|c|c|c|c|c|c|c|}
\hline \multirow{2}{*}{ OpERATION } & \multicolumn{2}{|c|}{ GROUP 1} & \multicolumn{2}{|c|}{ Group 2} & \multicolumn{2}{|c|}{ GROUP 3} & \multicolumn{2}{|c|}{ Averages } \\
\hline & A & B & A & B & A & B & A & B \\
\hline Addition $\ldots \ldots \ldots \ldots \ldots$ & 11.6 & 14.8 & 12.0 & 14.7 & 11.8 & 15.1 & 11.8 & 14.8 \\
\hline Subtraction .......... & 8.2 & 10.6 & 8.4 & 10.3 & 7.9 & 10.5 & 8.2 & 10.5 \\
\hline Multiplication......... & 8.5 & 12.2 & 8.3 & 12.0 & 8.1 & 12.4 & 8.3 & 12.2 \\
\hline Division............ & 5.5 & 8.5 & 5.9 & 8.0 & 6.1 & 8.8 & 5.8 & 8.4 \\
\hline Mixed fundamentals..... & 21.0 & 25.9 & 21.0 & 26.1 & 22.2 & 27.0 & 21.4 & 26.3 \\
\hline
\end{tabular}

(b) Groups Using Practice Tests

\begin{tabular}{|c|c|c|c|c|c|c|c|c|}
\hline \multirow{2}{*}{ OPERATION } & \multicolumn{2}{|c|}{ GROUP 4} & \multicolumn{2}{|c|}{ GROUP 5} & \multicolumn{2}{|c|}{ GROUP 6} & \multicolumn{2}{|c|}{ AVERAGES } \\
\hline & A & B & A & B & A & B & A & B \\
\hline Addition.... & 11.9 & 16.0 & 11.7 & 15.8 & 11.7 & 16.3 & 11.8 & 16.0 \\
\hline Subtraction ... & 8.1 & 12.4 & 8.6 & 12.2 & 8.0 & 11.9 & 8.2 & 12.2 \\
\hline Multiplication. & 8.0 & 15.3 & 9.0 & 15.5 & 8.4 & 14.8 & 8.4 & 15.2 \\
\hline Division...... & 5.4 & 9.6 & 5.7 & 10.2 & 5.8 & 9.3 & 5.6 & 9.7 \\
\hline Mixed fundamentals.... & 22.0 & 29.0 & 19.5 & 30.0 & 23.0 & 29.6 & 21.5 & 29.5 \\
\hline
\end{tabular}

three teachers trained for the purpose were directed to use only the Courtis Standard Practice Tests for the drill, but to use them for all they were worth. None of the teachers had any inkling of the real object in view. Yet each one was keyed up to do her best after her own fashion. Every pupil in the six groups was promised a special holiday for not missing more than one day during the term. Pedagogically, of course, this may have been questionable, but psychologically it proved very effective; and I hoped that the end would justify the means. At any rate, I know that a large majority of the pupils got their holiday.

The work was supervised as closely as possible throughout the term. Neither from observation nor by questioning pupils could I detect any evidence that the rules of the game were being disregarded by any of the teachers. At the end of twelve weeks the pupils were again tested with the Woody scales. The average scores for each group were placed in the "B" columns of Table I in such a way that each group's second score in each subject was opposite its first score in the same subject. According to the 
table, the average score of the pupils of Group 1 on the first test in addition (Column A) was 11.6. The score for the same group in the second addition test was 14.8 as shown in the first " $B$ " column. The scores for the three groups which did not use the practice tests were averaged for both first and second tests; and they are recorded in the fourth " $A$ " and " $B$ " columns, while in like manner the general averages for the three groups which used the practice tests are recorded in the last two columns of the table.

It will be noted that, according to the " $\mathrm{A}$ " columns of the general averages, the two main groups, the first consisting of the three smaller groups in which the practice tests were not used, and the second, of the three groups in which they were used, started almost exactly even in the race as might be expected under the circumstances. The first score of both groups in addition was 11.8 and the first score in subtraction for each group was 8.2. The remaining first scores differed by but one or two tenths of a unit. But this correspondence is no longer apparent when the "B" columns of general averages are considered. The final scores of the group using the practice tests are seen to be considerably larger than those of the group not using them. The differences between the scores contained in the fourth and last " $\mathrm{B}$ " columns represent the difference in progress of the two main groups.

The group of pupils drilled with the practice tests has all the best of the argument, the difference in progress being sufficiently great to prove conclusively considerable superiority for the Courtis method properly handled. On the whole, the improvement of all the groups was surprisingly large for a period of only twelve weeks. It amounted on the average to about a year of progress for the groups which did not use the practice tests and to about a year and three-quarters for the group using the practice tests. This merely goes to show what can be accomplished by intensive work along definite lines when the interest of teachers and pupils has been thoroughly aroused.

Now to return to the second way in which we might want to compare special methods. Suppose we wish to learn which of two or three special methods will give the best results with a particular teacher. This is quite a different matter from measuring the relative efficiency of the methods themselves. Only in exceptional cases can methods be accurately compared when handled by the same teacher. For such a purpose the teacher must be equally skilled in the use of the methods to be compared 
and without prejudice in favor of any particular method. In particular she must have a thorough knowledge of the special advantages and disadvantages of each method and know how to minimize the latter and make the most of the former. In no other way can the methods be given a fair trial. Only an exceptionally well-trained and widely-experienced teacher, with the impartial mind of a scientist seeking truth through experiment, can fulfill these conditions. Such teachers are not to be found in every school system.

We know that quite often a method of teaching which has proved highly successful when handled by its originator or by teachers specially trained by him, has failed miserably when introduced into an alien school system where the teachers were trained and experienced in other methods. And such failure is not to be wondered at. When the mere form of a new method, without its spirit, is introduced among workers lacking a knowledge of the proper technic to accompany the method, and naturally prejudiced in favor of their own methods, the new method is foredoomed to failure. A few of the better teachers, specially endowed with adaptability and initiative, may grasp the essential advantages of the new method, gradually evolve a suitable technic to fit it, and adopt it as their own. But most teachers, finding themselves accomplishing less with the new method than they did with the old, and longing for the familiar routine, will, unless constant supervision prevents, return surreptitiously at least to their former procedure, convinced that there is none better and that attempting new methods is a waste of time and trying to the nerves.

Of course if the real interest of the teachers can be aroused in the new method by a judicious advertising campaign before it is introduced, and if everybody's patience holds out long enough, and a definite policy of teacher-selecting and teacher-training is carried on, eventually the new method will come into its own if it really possesses marked advantages. But in too many instances the innovation is discarded as worthless after a few months of half-hearted trial without any adequate attempt having been made to modify the environment to fit the new method. And the chief factors contributing to such failures in attempting to introduce new methods of teaching into a school system are the indifference of teachers or their actual antagonism toward new methods, in general, their lack of knowledge concerning 
particular new methods, and their lack of foresight and initiative in adapting themselves and their ideas to changing conditions. Probably the most annoying factor and the one most difficult to eliminate is the teacher's mental attitude toward new ways of doing things, her clinging to familiar trails, and her aversion to breaking new paths even in the interest of finding a smoother, shorter, and pleasanter road to her goal.

Hence new methods, unless real interest and belief in them have been aroused in the teacher beforehand, have to contend against ignorance and indifference or prejudice from the start. I repeat, therefore, that the efficiency of new methods cannot be accurately compared with that of old methods if the new ones are tested by the very teacher whose own methods are being questioned as to their comparative worth. Her attitude is too much like that of the hen defending her chickens from the hawk that would destroy them, the teacher's chickens being her own familiar methods while the hawk is the superintendent with his disturbing new ideas.

We can, however, determine pretty accurately which of two methods a teacher can (or will) handle most efficiently regardless of the actual possibilities inherent in the two methods. And since it is essential that each teacher use, in general, the methods with which she can produce the best results, it is also essential that we know what those methods are. It will not be found profitable, merely for the sake of having certain new methods, to enforce their continued use on teachers who cannot or will not produce as good results with them as they produce with their own methods. So we must have some way of determining whether or not teachers are doing as well or better with the new methods after using them a reasonable length of time, say six months or a year.

This can be done with the help of standardized tests. First select ten or a dozen pupils in the school with mental ages and I.Q.'s as nearly equal as it is possible to arrange. Divide them into two equal groups that average about the same in mental ability. Next test them with some standardized tests in the subject for which special methods are to be compared. Then have the teacher try out two methods, one on each group of pupils, over a period of three or four months. At the end of that time give the tests again and compare the progress of the two groups. 
Such a trial will not necessarily prove which method is the better as regards possibilities, nor with which method the teacher could do better if she had the proper inclination and training, but it will prove with which method she will do better under existing conditions. And that is the essential point. If, after preparing carefully for the introduction of a new method of teaching some subject, by discussing its possibilities with teachers individually and collectively, and by furnishing them with suitable reading material concerning its basic principles, special advantages, and technic; if after demonstrating to the teachers the proper handling of the method and giving them a reasonable length of time to acquire skill in its use; and if after striving in every way to arouse their interest and hearty cooperation in giving the new method a thorough tryout; if after doing all these things and as many more as you can think of, you make such a comparison as outlined above and find that a teacher either cannot or will not do at least as good work with the new method as she did with the old, then it is time to discard either the teacher or the method. If your best teachers have succeeded in getting superior results by using the new method, it means that the method is all right and it may be wise to keep the method and get a new teacher. But if your best teachers have failed to get better results with the new method after several months of earnest effort, it will probably be better to discard the method.

At any rate, in order that the children may get the most for their time and the taxpayers the most for their money, it behooves us to make sure that the methods in use in the schools under our direction are the most efficient that can be used under existing circumstances. We can do this either by selecting and training teachers to fit our chosen methods or by selecting methods to fit the available teachers. Most emphatically it is not efficiency to cling to new methods forced upon untrained or improperly trained and often unwilling teachers just because they are up-todate methods, when those teachers are not doing as good work with them as with their own methods. Unless we can train our teachers successfully in the proper use of the new methods, or obtain teachers already trained in their use, we had better stick to the old a little longer. Standardized tests will help to prove whether or not the new methods are more successful than the old methods in a particular environment. Results are more important than methods. 